\title{
Involuntary Railway Crossing Controller
}

\author{
J.J. Mahakud, B.N. Sahoo, P. Pattanaik
}

\begin{abstract}
The main motive of this paper is to present an involuntary railway crossing controller that turn on and off the gates during crossing of trains. This reduces the physical efforts made by the gate keeper and saves a lot of time as well as money. In present times the station master has to communicate with gatekeeper to inform him to close gate and if train is late due to some reason, the public has to wait for a long until the train reaches the crossing thus an involuntary railway crossing controller is a solution of these problems. And most of the rail accident occurs due to carelessness or fault of gate keeper therefore, this proposed method also help to save lives of mankind by making the gate system autonomous. The involuntary controller is based on ATMEGA 328 microcontroller.
\end{abstract}

Index Terms-Railway crossing, ATMEGA 328 microcontroller, gatekeeper, autonomous gate.

\section{INTRODUCTION}

A Railway crossing is employed everywhere near the place from where a train crosses the public roads. Other names taken in are level crossing or grade crossing and it does not include any tunnel crossing, river crossing or bridge crossing. In Primary grade crossings a lag man is used to show red flag to the train for early stopping of train. The various type of track changing switches are also controlled by the leg man to divert the train whenever needed. Labor-intensive or electrically operated gateways that barred the road were presented later on [1]. The entrances were intended to be a broad barricade for restricting any roadways or heavy vehicles from entering into the railway track. In the conventional times of railways, large amount of road traffics were stopped by the crossing gates or barricades but it was very dangerous for the roadways as well as human lives to cross the railway track [2]. Most of the accident were happen due to wrong decision made by gate keeper. Thus, the minute when crossing gateways are closed for stopping the road traffic during crossing of train. When gate is open an enormous traffic crosses the wide road. With the arrival of vehicles, the barricade became less operative and the necessity for a barricade for cattle reduced intensely. Various nations had replaced the barrier crossings with delicate but further extremely observable barricades and trusted on motor vehicle rider to follow the related caution signals to stop [3],[4],[5]. In this paper an involuntary railway crossing controller is designed. The controller used is ATMEGA 328

Revised Manuscript Received on September 10, 2019.

J.J. Mahakud, Dept. of Electronics \& Comm Engineering, Siksha O Anusandhan Deemed to be University, Odisha, India.

(Email: jeevanmahakud@soa.ac.in)

B.N. Sahoo, Dept. of Electronics \& Comm Engineering, Siksha O Anusandhan Deemed to be University, Odisha, India.

(Email: badrinarayansahu@soa.ac.in)

P. Pattanaik, Dept. of Electronics \& Comm Engineering, Siksha O Anusandhan Deemed to be University, Odisha, India.

(Email: priyabratapattanaik@soa.ac.in) microcontroller with a plurality of IR transmitter along with pairs of receivers.

\section{WORKING OF INVOLUNTARY RAILWAY CROSSING CONTROLLER \& RESULTS}

The controller which is designed is 328 microcontrollers for the purpose of automatically controlling of railway crossing without making much efforts [6],[7]. The rate of accident can be reduced to $90 \%$ by using this proposed method. In this project an ATMEGA328 microcontroller is associated with two infra-red transmitters and two pair of receivers. First pair is fixed at the position from where the train arrives and second pair is placed below the train direction. When train is near $1 \mathrm{~km}$ of railway crossing then the first sensor will get activated and send signal to microcontroller for closing the gate of railway crossing. When the train crosses the gate than after the distance of 1 $\mathrm{km}$ the second sensor gets activated and sends the command to microcontroller for reopening the gate of railway crossing. The alarm system is also installed and actuated if there are mis happening and alert the driver of the train to stop immediately.

\section{i) Block diagram}

A $5 \mathrm{v}$ de supply is given to ATMEGA 328 microcontroller, for this purpose a transformer is used to stepdown $220 \mathrm{v}$ to $5 \mathrm{v}$ and rectifier circuit converts ac voltage into dc. The two sensors i.e. sensor 1 and sensor 2 also known as upside and downside sensors are connected to microcontroller for sending the signal of train arrival and departure.

After the processing of mirocontroller, two motor controllers also known as $\mathrm{H}$ bridge controller circuit is connected to a dc motor for moving the motor at a particular direction and a 5 volt dc motor is linked with the $\mathrm{H}$ bridge controller.

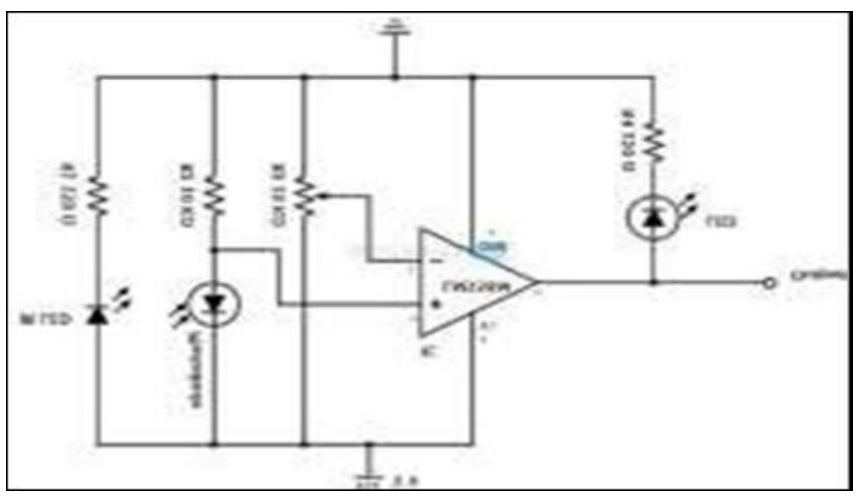

FIG.1 BLOCK DIAGRAM OF RAILWAY CROSSING CONTROLLER 
ii)

IR Transmitter

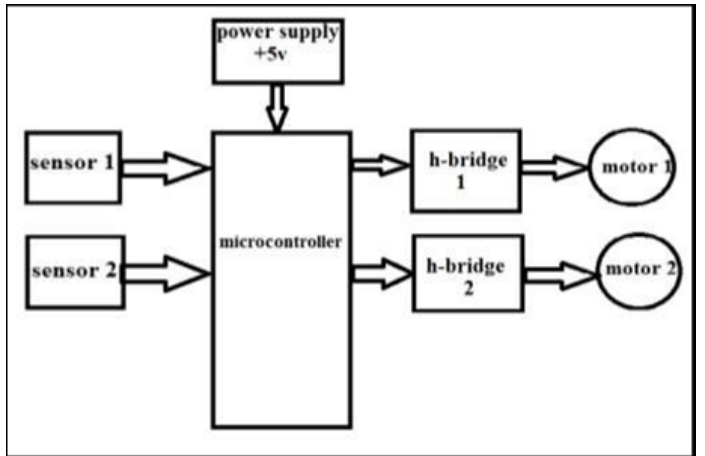

FIG. 2 POWER SUPPLY UNIT

IR transmitter is basically a inferred sensor which is used to sense an obstacle which comes near to it. It also senses the heat and detect the movement of moving objects. It ranges from 1 meter to 5 meters [10].

The light of these sensors is not visible by our necked eyes and are made up of light emitting diode. Fig.3 represent the circuit diagram of IR transmitter.

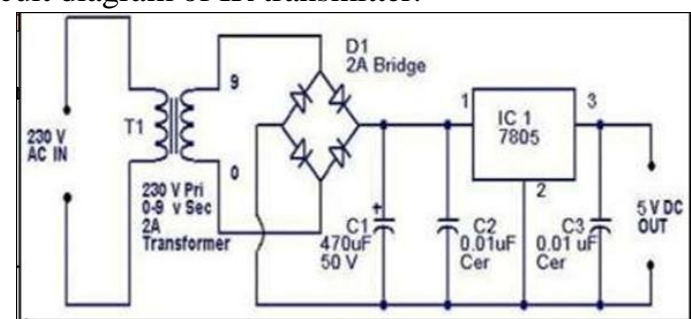

Fig.3 Circuit diagram of IR Transmitter

iii) H Bridge motor controller

The H-Bridge circuit generally used to give the motion to a dc motor shaft to move in a particular direction. During the operation mode Q1 and Q4 which is connected on the left pin of the motor gives a power supply and right side pin is connected to the ground current which is helps a dc motor shaft to rotate in forward and backward direction [8],[9]. The circuit diagram of $\mathrm{H}$ bridge is shown below-

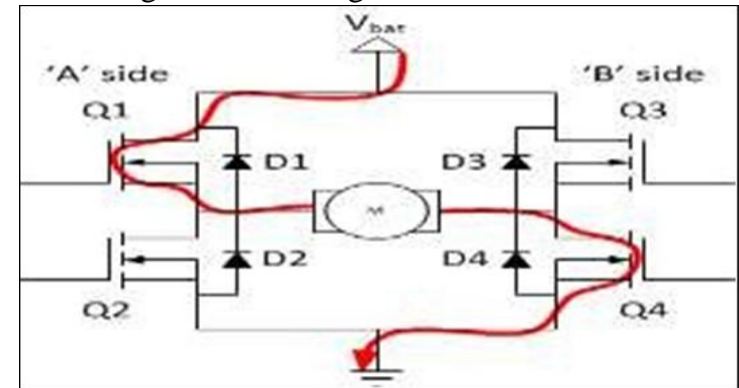

Fig.4(a) Circuit diagram of $\mathrm{H}$-bridge when Q1 and Q4

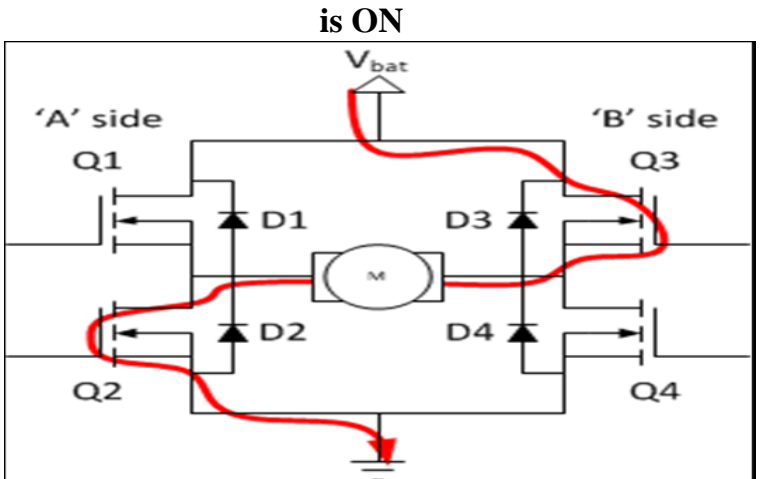

Fig.4(b) Circuit diagram of $\mathrm{H}$-bridge when Q2 and Q3 is $\mathbf{O N}$
Fig.4(a) shows the circuit diagram of H-bridge when Q1 and Q4 is turn ON and the motor will motor gets excited in forward direction due to which its shaft will spin in forward direction.

Fig.4(b) represent the circuit diagram of $\mathrm{H}$ - bridge when Q2 and Q3 are in ON position, in this case the motor will excited in backward direction and its shaft will also spin in backward direction[8],[11].

\section{iv) $15 \mathrm{rpm} \mathrm{DC} \mathrm{motor}$}

A $5 \mathrm{v}, 15 \mathrm{rpm}, \mathrm{DC}$ motor is used in this project. The $\mathrm{dc}$ motor is basically a dc geared motor used for high starting torque in various application. The controlling of dc motor is very simple and is very fast in response.

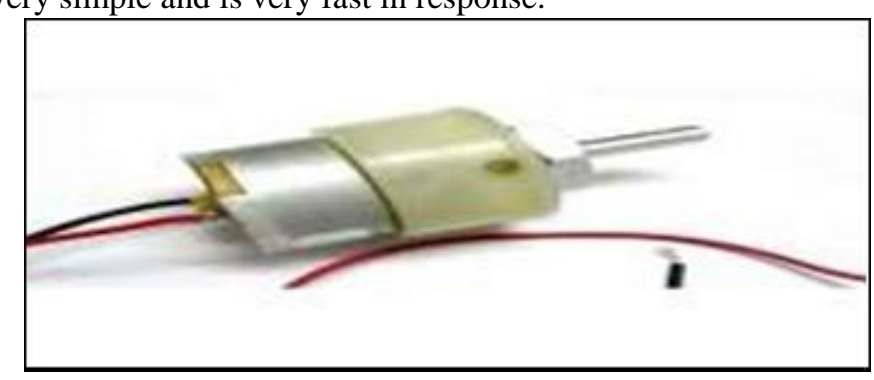

Fig.5 15v Dc geared motor

v) ATMEGA 328 Microcontroller

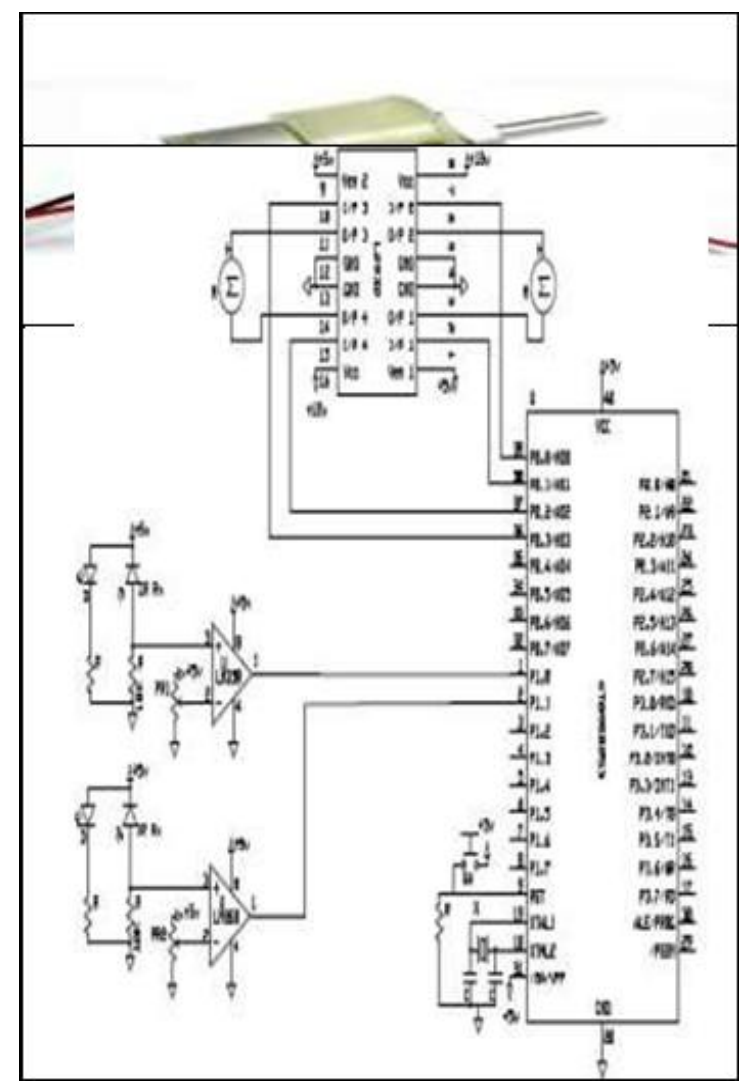

Fig.6 Circuit diagram of ATMEGA328 microcontroller

ATMEGA 328 comprises of 14 digital input/output pins and 20 analog pins. All the components such as motor, $\mathrm{H}$ bridge controller, IR sensor are assembled within the microcontroller. IR transmitter and buzzer are connected to

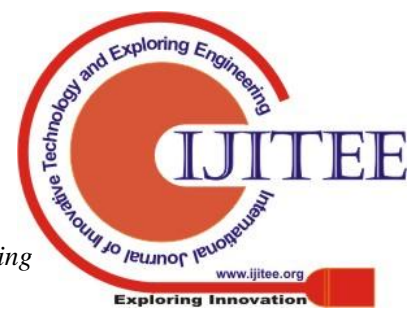


the digital pin and de motor is connected to analog pin. When IR sensors detect any object, it sends signal to the microcontroller. The microcontroller after processing gives instructions to $\mathrm{H}$ bridge controller to control the motion of dc geared motor [10],[11],[12].

The I/O port allows sensors to input the data and after certain time of processing gives output signal at output port.

- The ADC allows to receives the analog signals from power supply and convert it into dc for further processing.

- A reset pin is given to restart whole of the controller again in case of malfunctioning.

\section{vi) Hardware Unit}

Railways are the most economical existence in a world for the purpose of travelling from once place to other. Whereas the other means like roadways, airways and waterways are not economical as compared to railways. when we see news on daily basis, we found that a majority of accident happen in railway crossing. The main reason behind these types of accident is due to the sloppiness of the gate keeper of railway crossing and also due to the lack of communication between station master and gate keeper. Therefore, for eliminating these accidents at railway crossing a novel involuntary railway crossing controller is developed which provide a complete safety from accident. The hardware unit comprises of two IR sensors, first IR sensor or transmitter is used to detect the arrival of train and placed $1 \mathrm{~km}$ before the railway crossing. When trains get closer to first IR sensor, it sends signal to the microcontroller and the microcontroller gives instruction to motor to close the gate of railway crossing. The second sensor is placed $1 \mathrm{~km}$ away the railway crossing. When the train crosses the railway crossing and reaches near the second sensor, it gives the signal to microcontroller and the microcontroller orders the $\mathrm{H}$ bridge to control the motor and open the gates.

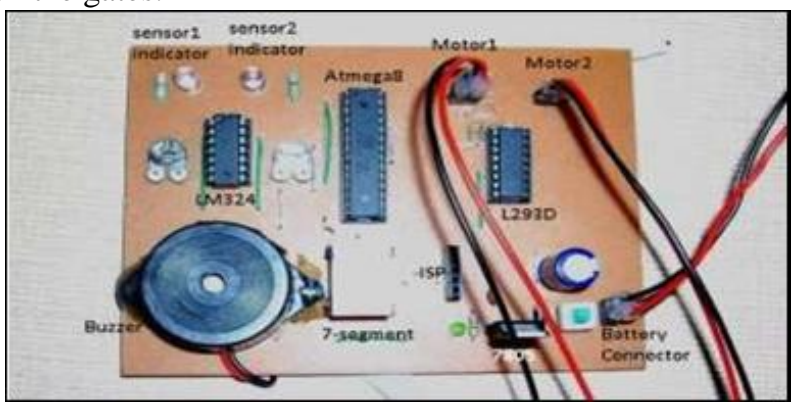

Fig. 7(a) circuit diagram

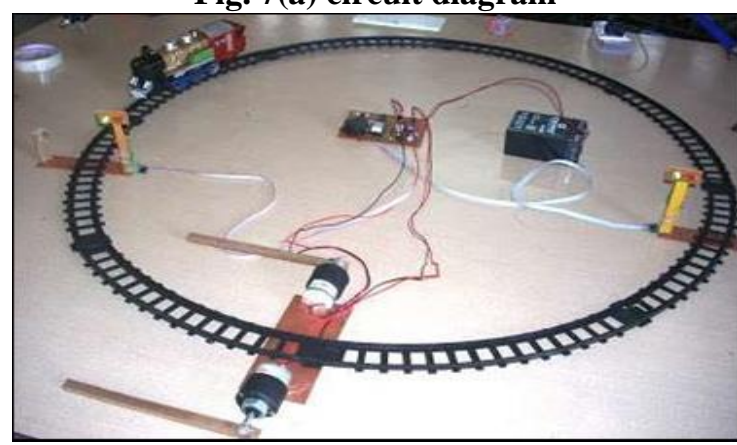

Fig. 7(b) Hardware unit

\section{CONCLUSION}

This paper proposes a modern and novel involuntary railway crossing controller which have many advantages over conventional railway crossing barricade. It reduces the railways accident, provides safety to animals while crossing the railway tracks, eliminates the manual operation of legman who closes and opens the barricade manually. Conventionally when train arrives near the crossing barricade, the station master has to call to the gate person to close the barricade manually and if during this process there is any miscommunication between them will result in accident. Therefore, by introducing this involuntary railway crossing controller, there is no need of person who has to open and close the gate. Everything will be control in an automatic manner with less cost and no physical effort.

\section{REFERENCES}

1. D. S. Armstrong and J. D. Francis, "Railways," in Electrical Engineer's Reference Book: Sixteenth Edition, 2003.

2. Branch Rail Accident Investigation, "Rail Accident Report," Branch, Rail Accid. Investig., 2009.

3. W. Evans, "Rail safety and rail privatisation in Japan," Accid. Anal. Prev., 2010.

4. Ajay.V. Deshmukh, Microcontrollers (Theory and Application), Tata McGraw-Hill Publication, 2005.

5. Ahmed Salih Mahdi, Al-Zuhairi, Automatic Railway Gate and Crossing Control based Sensors \&Microcontroller, International Journal of Computer Trends and Technology (IJCTT), 2013, 4; (7). 2013.

6. Banuchandar J, Kaliraj V, Balasubramanian P, Deepa S, Thamilarasi N, Automated Unmanned Railway Level Crossing System, International Journal of Modern Engineering Research (IJMER), 2012, 2 (1); 458-463.

7. Fred Coleman, Young J. Moon, Trapped Vehicle Detection System for Four Quadrant Gates in High Speed Rail Corridors, Transportation Research Record, 2011.

8. Fred Coleman, Young J. Moon, Design of Gate Delay and Gate Interval Time for Four Quadrant Gate System at Railroad-Highway Grade Crossings Transportation Research Record, 2010.

9. Krishna, Shashi Yadav and Nidhi, Automatic Railway Gate Control using Microcontroller", Oriental Journal of Computer Science \& Technology, 2013, 6; 4.

10. V.K. Mehta, Principles of Electronics, 11th edition, S Chand and Company, S.R.M University, 2009

11. Muhammad Ali Mazidi, Janice GillispieMazidi, Rolin.D. McKinlay, The 8051 Microcontrollers and Embedded System, 2nd edition Pearson Education, 2008

12. Paul.G. Slade, Electrical Contacts: Principles and Applications, 2nd edition CRC Press Taylor \& Francis group, 2013 